\title{
manejo de Tiririca e Trapoeraba com Glyphosate em Ambientes SOMBREADOS ${ }^{1}$
}

\author{
Commelina benghalensis and Cyperus rotundus Treated with Glyphosate in Shaded \\ Environments
}

\author{
SANTOS JÚNIOR, A. ${ }^{2}$, TUFFI SANTOS, L.D. ${ }^{3}$, COSTA, G.A. ${ }^{4}$, BARBOSA, E.A. ${ }^{5}$, LEITE, G.L.D. ${ }^{3}$, \\ MACHADO, V.D. ${ }^{6}$ e CRUZ, L.R. ${ }^{7}$
}

\begin{abstract}
RESUMO - Plantas daninhas mantidas em ambientes com redução da intensidade luminosa apresentam alterações morfofisiológicas marcantes, que podem alterar seu comportamento reprodutivo e a tolerância a herbicidas aplicados em pós-emergência. Objetivou-se neste estudo avaliar a eficiência de doses de glyphosate no manejo da trapoeraba (Commelina benghalensis) e da tiririca (Cyperus rotundus) cultivadas em diferentes niveis de sombreamento. O trabalho foi composto por dois ensaios, referentes a cada uma das espécies, com o mesmo delineamento experimental, sendo constituídos em esquema fatorial $5 \times 3$, com cinco doses de herbicida $\left(0,540,810,1.080\right.$ ou $1.350 \mathrm{~g} \mathrm{ha}^{-1}$ de glyphosate), três ambientes de cultivo $(0$, 30 ou $50 \%$ de sombra) e quatro repetições. As parcelas experimentais foram compostas por um vaso com duas plantas de tiririca ou de trapoeraba. As avaliações de controle ocorreram aos 10, 20 e 30 dias após a aplicação (DAA), por meio de observações visuais. Aos 30 DAA, foi determinada a massa seca da parte aérea de cada espécie. A produtividade de tubérculos foi observada pela contagem direta desses propágulos presentes nas raizes das plantas de tiririca. Já a sua viabilidade foi avaliada por teste de germinação em leito de areia e por tetrazólio no caso dos não germinados. O controle das espécies foi mais eficiente em ambientes sombreados, contribuindo para a redução de até $25 \%$ da dose recomendada para ambas, obtendo-se controle de $81 \%$ para trapoeraba e 100\% para tiririca. Já a matéria seca da parte aérea, a produtividade e a viabilidade dos tubérculos foram afetadas pelo aumento do nivel de sombra e pela dose de glyphosate. A diminuição da intensidade luminosa - comum no sub-bosque de culturas arbóreas e arbustivas ou quando do adensamento de cultivos representa prática interessante na supressão da trapoeraba e da tiririca e potencializa a ação de controle do glyphosate.
\end{abstract}

Palavras-chave: ecofisiologia, controle químico, tolerância, sombra.

\begin{abstract}
Weeds maintained in reduced light intensity environments present remarkable morphophysiological changes that may alter their reproductive behavior and tolerance to post-emergence herbicides. Our goal was to evaluate the efficiency of glyphosate doses in the management of Commelina benghalensis and Cyperus rotundus grown at different levels of shading. The work consisted of two trials for each species with the same experimental design, in a $5 \times 3$ factorial design with five herbicide doses $\left(0,540,810,1.080\right.$, and $1.350 \mathrm{~g} \mathrm{ha}^{-1}$ of glyphosate), three cultivation environments (0,30, or $50 \%$ of shading) and four replicates. Experimental plots consisted of a vase with two plants of either $\boldsymbol{C}$. benghalensis or C. rotundus. Control evaluations were carried out 10, 20, and 30 days after application (DAA) through visual observations. Tuber productivity was verified by direct counting of these propagules present in the roots of $\mathbf{C}$. rotundus plants, while tuber viability was evaluated by germination test in a sand bed, and by tetrazolium, for the nongerminated tubers. Species control was more efficient in shade environments, contributing to a reduction of up to $25 \%$ of the recommended dose for the treated species, and resulting in a control
\end{abstract}

Recebido para publicação em 13.4.2012 e aprovado em 30.8.2012.

2 Mestrando em Fitotecnia pela Universidade Federal de Viçosa - DFT/UFV. ${ }^{3}$ Professor, ICA/UFMG, <ltuffi@ufmg.br>; ${ }^{4}$ Engo-Agro ${ }^{\circ}$ Autônomo; ${ }^{5}$ Mestrando em Produção Vegetal pela UFVJM; ${ }^{6}$ Mestrando em Zootecnia pela UFV; ${ }^{7}$ Graduando em Agronomia, Instituto de Ciências Agrárias, Universidade Federal de Minas Gerais - ICA/UFMG, Campus de Montes Claros-MG, Av. Universitária, 1000, 39404-006 Bairro Universitário. 
of $81 \%$ for C. benghalensis and $100 \%$ for C. rotundus. Aerial part dry biomass and productivity and viability oftubers were affected by increase in shade level and glyphosate dose. Reduced light intensity - common in the under-story of tree and shrub cultures or in culture density - is an interesting practice aiming at suppressing C. benghalensis and C. rotundus, acting as a potential control of glyphosate.

Keywords: ecophysiology, chemical control, tolerance, shade.

\section{INTRODUÇÃO}

As características morfofisiológicas, o crescimento e o desenvolvimento das plantas daninhas são diretamente influenciados pelo meio em que elas vivem. Em ambientes sombreados, existem relatos de alterações como a diminuição nos espaços intracelulares no mesofilo, o aumento na área do limbo foliar, o maior número de estômatos, a diminuição da espessura das folhas, a cutícula mais fina na epiderme e a menor deposição de ceras (Santos et al., 2001; Lima Jr. et al., 2006; Gondim et al., 2008; Taiz \& Zeiger, 2009). Essas mudanças possuem envolvimento direto na interceptação, penetração ou absorção de herbicidas aplicados nas folhas, como os produtos à base de glyphosate.

Esse herbicida é o mais utilizado na agricultura mundial, devido ao seu baixo custo, ao amplo espectro de ação e por causar menor impacto ao meio ambiente em relação a outros herbicidas (Malik et al., 1989). Observações de campo indicam maior efeito desse herbicida no controle de plantas daninhas quando sombreadas. Ainda que relevante para o manejo da matocompetição, a recomendação das doses de glyphosate para o controle das plantas daninhas não leva em consideração o nivel de luminosidade - condição comum em algumas culturas arbóreas e arbustivas.

O conhecimento do comportamento da flora daninha quando sujeita a baixa intensidade luminosa é fundamental para recomendar as doses de herbicidas, o que pode gerar economia em produtos químicos e, consequentemente, diminuição dos impactos sobre o meio ambiente. Embora seja de extrema importância o manejo das plantas daninhas em ambientes com déficit de luz, poucas são as pesquisas que visam elucidar a sua eficiência em espécies como a tiririca (Cyperus rotundus-Cyperaceae) e a trapoeraba
(Commelina benghalensis - Commelinaceae), consideradas de dificil controle e de ampla distribuição (Tuffi Santos et al., 2004; Durigan et al., 2006).

Nesse contexto, objetivou-se com este trabalho avaliar a eficiência de doses de glyphosate no manejo da tiririca e trapoeraba em diferentes niveis de sombreamento, bem como o acúmulo de matéria seca da parte aérea, a viabilidade e a produtividade dos tubérculos de tiririca, quando produzidos em ambiente sombreado e com ação desse herbicida.

\section{MATERIAL E MÉTODOS}

O experimento foi desenvolvido no município de Montes Claros-MG, localizado na longitude de $43^{\circ} 51^{\prime} 53^{\prime \prime} \mathrm{W}$, na latitude de $16^{\circ} 44^{\prime} 13^{\prime \prime} \mathrm{S}$ e a $650 \mathrm{~m}$ de altitude, no ano agrícola de 2010. De acordo com a classificação de Köppen, o clima da região é do tipo Aw tropical de savana. Os dados climáticos do período de realização do ensaio são apresentados na Figura 1.

As espécies utilizadas foram a tiririca (Cyperus rotundus) e a trapoeraba (Commelinea benghalensis), cultivadas entre os meses de abril e novembro de 2010. As mudas de tiririca foram obtidas por meio de tubérculos sadios, coletados em campo e padronizados quanto ao tamanho aproximado de $1,4 \mathrm{~cm}$ de comprimento, sendo posteriormente semeados em leito de areia. Já as mudas de trapoeraba foram produzidas por meio de estacas retiradas de ramos vigorosos de plantas encontradas no campus, medindo aproximadamente $6 \mathrm{~cm}$ de comprimento, com dois nós e um par de folhas expandidas cortadas ao meio e plantadas em bandejas contendo substrato de fibra de coco. As bandejas com os propágulos de ambas as espécies foram mantidas em leito de enraizamento, com irrigação por microasperção por 


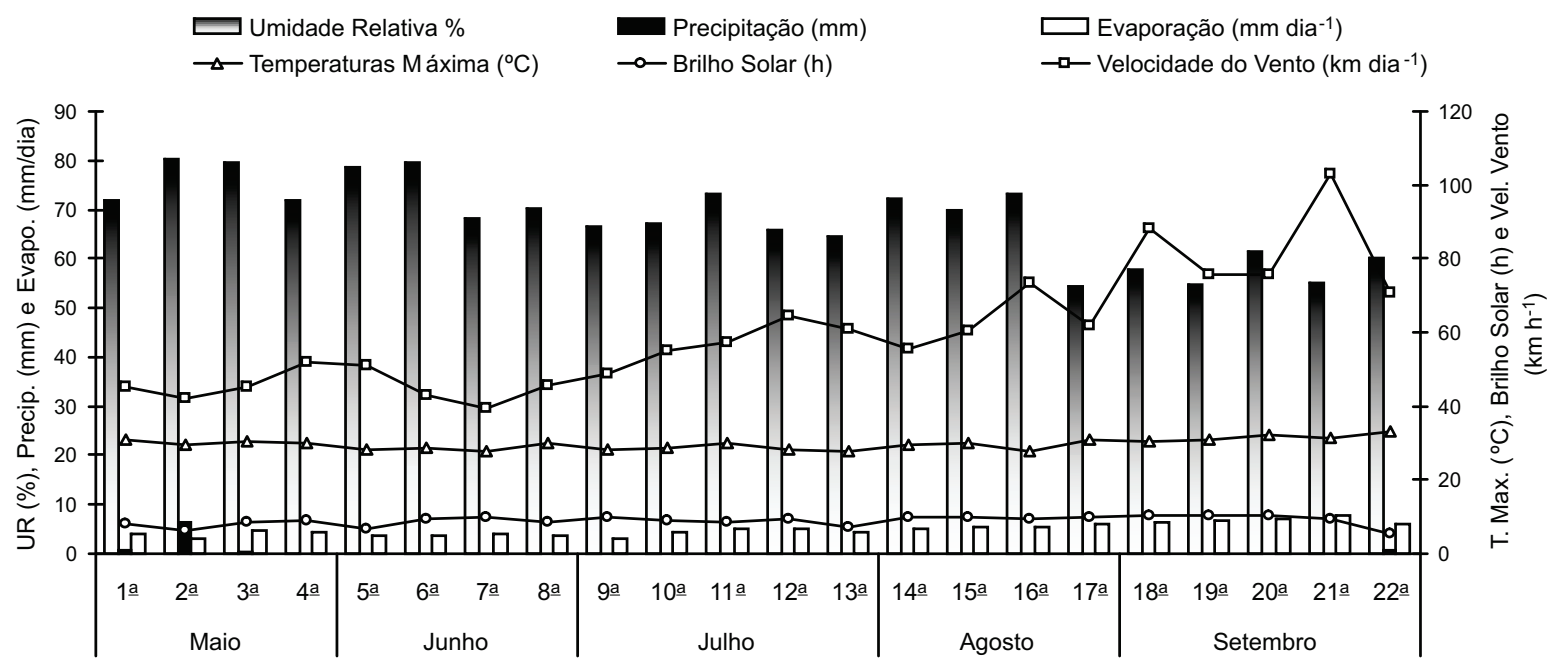

Figura 1 - Médias semanais de umidade relativa (\%), precipitação (mm), evaporação (mm dia $\left.{ }^{-1}\right)$, temperatura máxima $\left({ }^{\circ} \mathrm{C}\right)$, brilho solar (h) e vento $\left(\mathrm{km} \mathrm{dia}^{-1}\right)$ obtidas durante o período de condução do experimento.

30 dias. Após esse período, duas mudas de trapoeraba foram transplantadas para vasos de nove litros, o mesmo ocorrendo para tiririca, porém em vasos de seis litros. Nos dois ensaios, os vasos foram preenchidos com o substrato terra: areia: esterco bovino curtido, na proporção de $3: 1: 1$, e $10 \mathrm{~kg}$ de NPK - formulado 4:30:10 em 0,9 $\mathrm{m}^{-3}$ de substrato.

O trabalho de controle de plantas daninhas sombreadas foi dividido em dois ensaios, referentes a cada uma das espécies, com o mesmo delineamento experimental. Os ensaios foram conduzidos em esquema fatorial $5 \times 3$, com o fator dose $\left(0,540,810,1.080\right.$ ou $1.350 \mathrm{~g} \mathrm{ha}^{-1}$ de glyphosate) e o fator ambiente (niveis de sombreamento 0, 30 ou $50 \%$ ). Eles foram distribuídos em blocos casualizados com quatro repetições, e cada parcela constituiu-se de duas plantas de tiririca ou trapoeraba.

Para obtenção dos ambientes, foram utilizadas telas sombrites de polipropileno, cor preta, com 30 ou $50 \%$ de sombreamento e a pleno sol. Após o transplantio das mudas, os vasos foram dispostos em seus respectivos ambientes de cultivo.

As plantas de tiririca e trapoeraba foram submetidas à poda aos 100 dias após o transplantio, para uniformização do desenvolvimento vegetativo; 25 dias depois da poda foi realizada a aplicação da calda herbicida. Para essa atividade, utilizou-se o pulverizador costal equipado com barra, uma ponta modelo
Teejet AI 110015 e válvula reguladora de pressão constante a $150 \mathrm{KPa}$, com o volume de $100 \mathrm{~L} \mathrm{ha}^{-1}$ de calda.

As avaliações foram realizadas aos 10, 20 e 30 dias após a aplicação (DAA), por meio de observações visuais de controle (ALAM, 1974), em que se adota escala de 0 a $100 \%$, sendo 0 ausência de intoxicação causada pelo herbicida e 100 a morte da planta.

Para determinação da matéria seca, coletaram-se todos os resquícios de vegetação remanescente no vaso após a avaliação de controle aos 30 DAA, a qual foi acondicionada em estufa com circulação forçada a $65 \pm 3{ }^{\circ} \mathrm{C}$ por 72 horas, até atingir o peso constante.

O tamanho dos tubérculos e a produtividade foram mensurados, respectivamente, de acordo com o seu comprimento, que variou entre pequeno (até $0,7 \mathrm{~cm})$, médio $(0,7 \mathrm{a}$ $1,4 \mathrm{~cm})$ e grande $(1,4$ a $2,1 \mathrm{~cm})$, e a contagem direta deles. Em cada unidade experimental, dos tubérculos previamente classificados, foram selecionados ao acaso 30 de cada tamanho, os quais foram dispostos em leito de areia durante 60 dias para avaliação da germinação. Foram considerados germinados os tubérculos que apresentavam parte aérea com no mínimo $1,0 \mathrm{~cm}$ de comprimento (Novo et al., 2008). Após esse periodo, submeteram-se os tubérculos não germinados ao teste de tetrazólio, em solução aquosa de $0,1 \%$ do sal de tetrazólio; eles foram acondicionados em BOD a 
$30{ }^{\circ} \mathrm{C}$ por 1,5 hora para determinação de sua viabilidade, sendo considerados viáveis aqueles que se coloriam de rosa em comparação à amostra-padrão (Novo et al., 2008; Martins et al., 2009).

Os dados obtidos foram submetidos ao teste de homocedasticidade e, em seguida, à análise de variância, com as médias das interações entre os fatores dose $\mathrm{x}$ ambiente de cultivo comparadas pelo teste de Tukey a $5 \%$ de probabilidade, bem como o efeito do fator ambiente de cultivo. Para os resultados referentes ao efeito isolado da dose de glyphosate, foram ajustados modelos de regressão, testando-se os coeficientes até $10 \%$ de probabilidade pelo teste $\mathrm{t}$.

\section{RESULTADOS E DISCUSSÃO}

\section{Manejo de trapoeraba (Commelina benghalensis) com glyphosate em ambientes}

A interação entre ambiente de cultivo e dose aplicada não foi significativa no controle da trapoeraba, aos 10 e 20 dias após aplicação (DAA). No entanto, aos 30 DAA, houve interação entre o ambiente e a dose $(P \leq 0,05)$ : plantas pulverizadas com 1.080 e $1.350 \mathrm{~g} \mathrm{ha}^{-1}$ de glyphosate a $50 \%$ de sombreamento obtiveram respostas superiores de controle em relação aos demais ambientes (Tabela 1). Plantas de trapoeraba mantidas em pleno sol apresentaram-se mais tolerantes à ação do glyphosate, quando comparadas àquelas plantas mantidas sob sombreamento, independentemente da dose de herbicida utilizada

Tabela 1 - Controle (\%) de trapoeraba (Commelina benghalensis) submetida a doses de glyphosate, em função do ambiente de crescimento à sombra ou a pleno sol, aos 30 DAA (dias após aplicação)

\begin{tabular}{|l|c|c|c|c|}
\hline \multirow{3}{*}{ Ambiente } & \multicolumn{4}{|c|}{ Dose $\left(\mathrm{g} \mathrm{ha}^{-1}\right.$ de glyphosate) } \\
\cline { 2 - 5 } & 540 & 810 & 1.080 & 1.350 \\
\cline { 2 - 5 } & \multicolumn{4}{|c}{ Controle aos 30 DAA } \\
\hline Pleno sol & $7,50 \mathrm{BCa}$ & $15,00 \mathrm{Bb}$ & $30,00 \mathrm{Ac}$ & $32,50 \mathrm{Ab}$ \\
\hline $30 \%$ de sombra & $11,25 \mathrm{Ba}$ & $50,00 \mathrm{Aa}$ & $56,25 \mathrm{Ab}$ & $56,45 \mathrm{Aa}$ \\
\hline $50 \%$ de sombra & $13,75 \mathrm{Ca}$ & $53,75 \mathrm{Ba}$ & $85,00 \mathrm{Aa}$ & $72,50 \mathrm{Aa}$ \\
\hline
\end{tabular}

Médias seguidas pelas mesmas letras, maiúsculas na linha e minúsculas na coluna, não diferem entre si pelo teste de Tukey a $5 \%$ de probabilidade.
(Tabela 1). O aumento do controle da trapoeraba sob sombra pode estar relacionado com as alterações morfofisiológicas ocorridas em suas estruturas celulares, levando a planta a investir mais recursos para aumentar a sua área fotossintética, em relação à sua proteção. Entre essas modificações atribuídas ao estresse luminoso estão a menor deposição de ceras epicuticulares hidrofóbicas na epiderme, o aumento da lâmina foliar e das estruturas secretoras presentes nesta e da permeabilidade das células na base dos tricomas, garantindo maior tempo de exposição da calda química e redução das barreiras à penetração desta (Sargent \& Blackman, 1962; Santos et al., 2002; Monquero et al., 2004a; Gobbi et al., 2009).

Não houve efeito do ambiente de cultivo no controle de trapoeraba nas observações realizadas aos 10 e 20 DAA, sendo ajustadas equações de regressão para o efeito das doses de glyphosate aplicadas (Figura 2). A baixa eficiência no controle da trapoeraba pode ser atribuída ao estádio de desenvolvimento das plantas e/ou à tolerância natural da espécie. Adicionalmente, o uso indiscriminado dos inibidores de EPSPs (5-enolpiruvilshiquimato3-fosfato sintase) tem selecionado genótipos mais tolerantes de espécies do gênero Commelina (Monquero \& Christoffoleti, 2003;

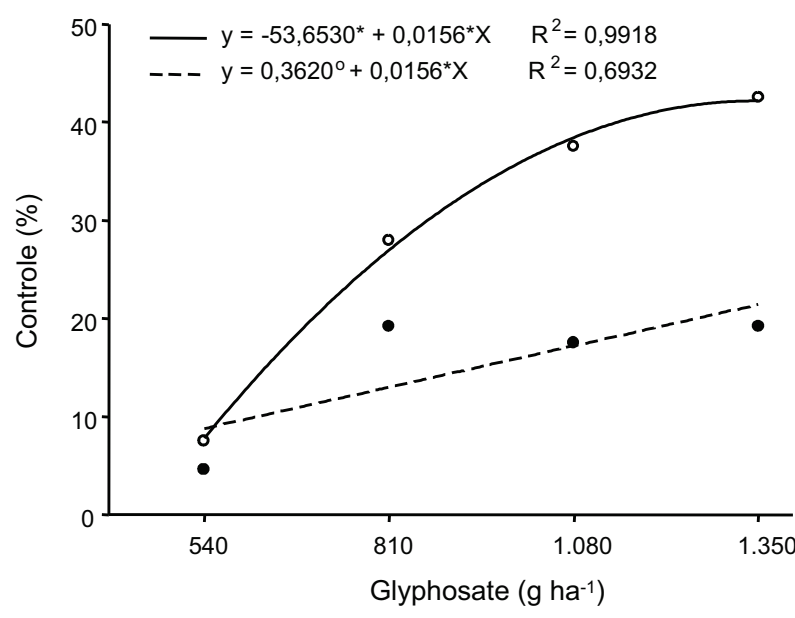

Média das quatro repetições, $-\mathbf{e}$ - aos $10 \mathrm{DAA}$ e $-\mathrm{O}$ - aos $20 \mathrm{DAA}$. ${ }^{0}$ a $10 \%$, * a $5 \%$ e $* *$ a $1 \%$ de significância.

Figura 2 - Porcentagem de controle da trapoeraba crescida em ambientes sombreados e a pleno sol, em função de doses de glyphosate. 
Monquero et al., 2004b), o que pode ter ocorrido com o acesso utilizado, que foi coletado em área de fruticultura frequentemente pulverizada com esse herbicida. Esse fato explicaria a diferença na eficiência de controle entre este trabalho e os reportados na literatura.

Santos et al. (2002), trabalhando com trapoeraba, alcançaram resultados superiores de eficiência no manejo em relação aos obtidos no presente ensaio, sendo observados $94,5 \%$ de controle com $720 \mathrm{~g} \mathrm{ha}^{-1}$ de glyphosate aos 25 DAA em ambiente desprotegido. Já Oliveira et al. (2009), trabalhando com duas formulações de glyphosate, obtiveram resultados que variavam de 21 a $30 \%$ utilizando $1.170 \mathrm{~g} \mathrm{ha}^{-1}$ de glyphosate, e de 61 a $80 \%$ com $1.440 \mathrm{~g} \mathrm{ha}^{-1}$ de glyphosate, ambos aos 21 DAA, em plantas de trapoeraba com 30 dias após o transplantio.

A restrição luminosa no ensaio, realizada com tela sombrite, ocorreu em periodo do ano de céu aberto, o que propiciou homogeneidade em relação às horas de brilho solar (Figura 1) durante a realização dos ensaios. Em outras situações, a presença de nuvens pode intensificar a restrição luminosa e, consecutivamente, afetar o crescimento da trapoeraba e favorecer seu controle com herbicida. Segundo Taiz \& Zeiger (2009), da energia solar incidente nas folhas, apenas $5 \%$ é convertida em carboidratos; logo, ambientes com restrição luminosa favorecem naturalmente o manejo de plantas daninhas.

O aumento das doses de glyphosate e do sombreamento influenciou significativamente o acúmulo de matéria seca das plantas de trapoeraba (Figura 3). A relação entre esses acúmulos na parte aérea de plantas a pleno sol foi 45,3 e $54 \%$ superior à de ambientes com 30 e $50 \%$ de sombreamento, respectivamente (Figura 3), devido à redução na atividade fotossintética e, consequentemente, à diminuição do carbono fixado, em decorrência da menor disponibilidade de energia disponível. Resultados semelhantes foram encontrados por Gobbi et al. (2009), que, trabalhando com Brachiaria decumbens a $50 \%$ de sombra, obtiveram redução em $15 \%$ de matéria seca quando comparada à de plantas cultivadas a pleno sol.

O estresse luminoso nas plantas desencadeia uma série de reações morfofisiológicas,

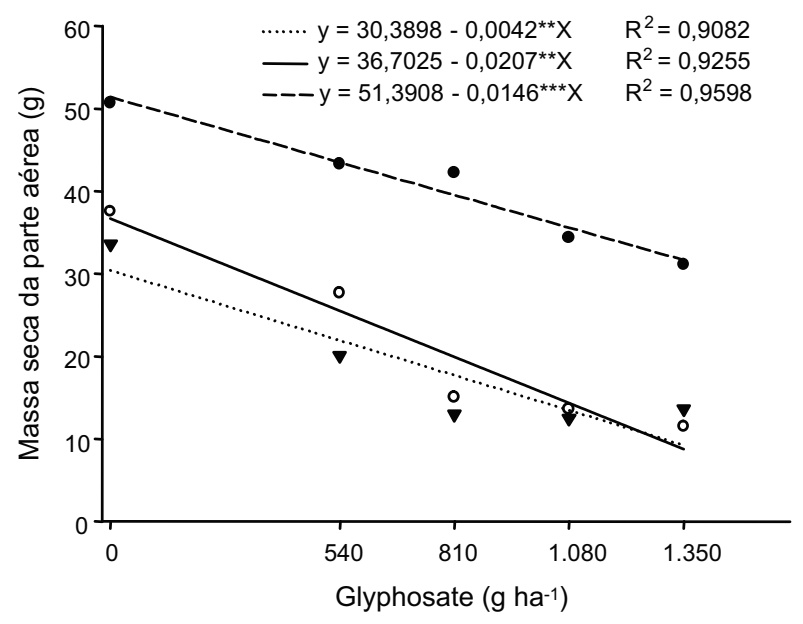

Média das quatro repetições, $-\mathbf{e}-$ pleno sol, $-\mathrm{O}-30 \%$ de sombra e $50 \%$ de sombra. ${ }^{* *}$ a $1 \%$ de significância.

Figura 3 - Massa seca da parte aérea de plantas de trapoeraba cultivadas à sombra e a pleno sol aos 30 dias após a aplicação de glyphosate.

envolvendo diminuição das taxas fotossintéticas e da respiração celular (Taiz \& Zeiger, 2009), proporcionando assim menor acúmulo de matéria seca e, consequentemente, maior controle, pois, com pouca reserva, a planta dificilmente irá se recuperar após a aplicação de um herbicida (Tuffi Santos et al., 2004).

\section{Manejo de tiririca (Cyperus rotundus) com} glyphosate em ambientes sombreados

O controle da tiririca com glyphosate foi influenciado $(\mathrm{P} \leq 0,05)$ pelos fatores isolados dose e ambiente de cultivo, bem como sua interação, em avaliações realizadas aos 10 , 20 e 30 DAA (Tabela 2).

As plantas cultivadas a $50 \%$ de sombra foram mais sensiveis às doses crescentes de glyphosate, alcançando $100 \%$ de controle aos 20 DAA (Tabela 2). A eficiência no controle com aplicação de $1.080 \mathrm{~g} \mathrm{ha}^{-1}$ de glyphosate a $50 \%$ de sombreamento aos 10 DAA foi 44,44 e $46,39 \%$ superior em relação aos ambientes a pleno sol e $30 \%$ de sombra, respectivamente (Tabela 2). Ao final da avaliação de controle da tiririca, realizada aos 30 DAA, não se observou diferença entre os ambientes de cultivo, sendo encontrados valores superiores e iguais entre si com a aplicação de doses acima de $810 \mathrm{~g} \mathrm{ha}^{-1}$ de glyphosate (Tabela 2). 
Tabela 2 - Controle (\%) de tiririca submetida a doses de glyphosate, em função do ambiente de crescimento à sombra ou a pleno sol

\begin{tabular}{|l|r|l|l|l|}
\hline \multirow{2}{*}{ Ambiente } & \multicolumn{5}{|c|}{ Dose $\left(\mathrm{g} \mathrm{ha}^{-1}\right.$ de glyphosate) } \\
\cline { 2 - 5 } & 540 & \multicolumn{1}{|c|}{810} & 1.080 & 1.350 \\
\hline \multicolumn{5}{|c|}{ Controle aos 10 DAA } \\
\hline Pleno sol & $8,75 \mathrm{Ba}$ & $16,25 \mathrm{Bb}$ & $50,00 \mathrm{Ab}$ & $61,25 \mathrm{Ab}$ \\
\hline $30 \%$ de sombra & $2,50 \mathrm{Ba}$ & $58,75 \mathrm{Aa}$ & $48,25 \mathrm{Ab}$ & $65,00 \mathrm{Aab}$ \\
\hline $50 \%$ de sombra & $13,75 \mathrm{Ba}$ & $41,25 \mathrm{Aa}$ & $90,00 \mathrm{Aa}$ & $78,75 \mathrm{Aa}$ \\
\hline \multicolumn{5}{|c|}{ Controle aos $20 \mathrm{DAA}$} \\
\hline Pleno sol & $36,25 \mathrm{Ca}$ & $63,75 \mathrm{Bb}$ & $82,50 \mathrm{ABab}$ & $94,25 \mathrm{Aa}$ \\
\hline $30 \%$ de sombra & $7,50 \mathrm{Cb}$ & $80,00 \mathrm{ABab}$ & $68,75 \mathrm{Bb}$ & $93,75 \mathrm{Aa}$ \\
\hline $50 \%$ de sombra & $53,75 \mathrm{Ba}$ & $91,25 \mathrm{Aa}$ & $100,00 \mathrm{Aa}$ & $99,50 \mathrm{Aa}$ \\
\hline \multicolumn{5}{|c}{$\mathrm{Controle}$ aos $30 \mathrm{DAA}$} \\
\hline Pleno sol & $72,50 \mathrm{Bc}$ & $91,25 \mathrm{Aa}$ & $91,75 \mathrm{Aa}$ & $95,25 \mathrm{Aa}$ \\
\hline $30 \%$ de sombra & $27,50 \mathrm{Bb}$ & $98,75 \mathrm{Aa}$ & $95,00 \mathrm{Aa}$ & $100,00 \mathrm{Aa}$ \\
\hline $50 \%$ de sombra & $78,25 \mathrm{Ba}$ & $98,25 \mathrm{Aa}$ & $100,00 \mathrm{Aa}$ & $100,00 \mathrm{Aa}$ \\
\hline
\end{tabular}

Letras minúsculas comparam médias entre ambientes na coluna e letras maiúsculas comparam médias entre doses de glyphosate nas linhas. Médias seguidas pelas mesmas letras, maiúsculas na linha e minúsculas na coluna, não diferem entre si pelo teste de Tukey a $5 \%$ de probabilidade.

Freitas et al. (1997) observaram redução de $68,9 \%$ no número de plantas de tiririca por vaso com a aplicação de $1.500 \mathrm{~g} \mathrm{ha}^{-1} \mathrm{de}$ glyphosate aos 20 dias após o plantio. Clemente (2009) verificou controle eficiente sobre a tiririca nas doses de 960 e $1.920 \mathrm{~g} \mathrm{ha}^{-1} \mathrm{de}$ glyphosate, porém com constatação de rebrota da espécie. No presente trabalho foi observado que, no geral, em plantas sombreadas o controle é mais rápido e eficiente (Tabela 2), o que possibilita o ajuste de doses inferiores à recomendada pelo fabricante, que é de $1.440 \mathrm{~g}^{\text {ha }}{ }^{-1}$ de glyphosate, com bons resultados no manejo.

Com o sombreamento, ocorrem alterações na morfologia e na estrutura foliar, como a expansão do limbo foliar, ocasionada pela turgidez e alongamento das células desse órgão, e a diminuição na deposição de ceras epicuticulares (Magalhães, 1967; Moosavinia \& Dore, 1979; Lima Jr. et al., 2006; Gondim et al., 2008; Gobbi et al., 2009). Essas mudanças são relacionadas à maior interceptação e absorção foliar de herbicidas aplicados em pós-emergência. Adicionalmente, o déficit luminoso reduz a eficiência do aparato fotossintético, ocasionando rearranjo na alocação dos fotoassimilados para a parte aérea, decorrente da demanda da planta em obter esse recurso escasso (Gondim et al., 2007). Assim, o crescimento das raízes e o acúmulo de reservas, tão importantes na recuperação das plantas frente à aplicação de herbicidas (Tuffi Santos et al., 2004), ficam prejudicados (Gondim et al., 2007).

$\mathrm{O}$ acúmulo de matéria seca pela tiririca foi influenciado pelo ambiente e pela dose de glyphosate (Figura 4), não sendo observada interação entre os fatores. Quando comparadas as testemunhas nos diferentes niveis de sombreamento, observa-se que o acúmulo médio de matéria seca a pleno sol foi 32,6 e $24,2 \%$ superior ao daquelas cultivadas a 30 e $50 \%$ de sombra, respectivamente (Figura 4). Esses dados corroboram os de Gobbi et al. (2009), que relataram diminuição do peso seco em espécies cultivadas sob déficit de luz. Esse comportamento deve-se à maior eficiência das plantas de metabolismo $\mathrm{C}_{4}$ na alocação e distribuição de fotoassimilidados, em razão do ponto de compensação de luz e das taxas fotossintéticas mais altas, ou seja, mais luz estimula o aumento da fotossintese (Taiz \& Zeiger, 2009).

O aumento da dose de glyphosate contribuiu para a redução no acúmulo de matéria seca da parte aérea da tiririca cultivada a pleno sol e à sombra, mesmo na menor dose desse herbicida (Figura 4). Segundo Jefferies (1965), plantas sombreadas não perdem água facilmente para o ambiente e apresentam

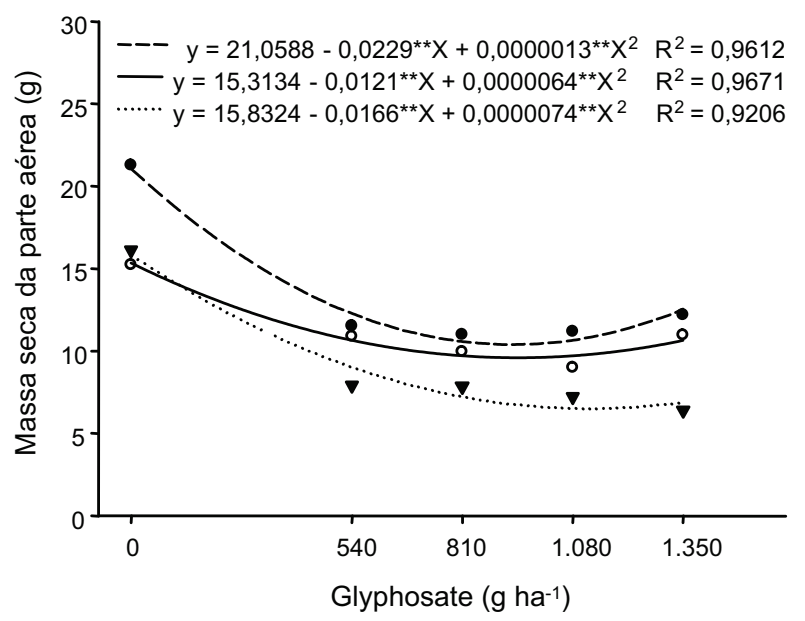

Média das quatro repetições, $-\mathbf{-}-$ pleno sol, $-\mathrm{O}-30 \%$ de sombra e $50 \%$ de sombra. ${ }^{* *}$ a $1 \%$ de significância.

Figura 4 - Massa seca da parte aérea de plantas de tiririca cultivadas à sombra e a pleno sol aos 30 dias após a aplicação de glyphosate. 
características particulares quanto à produção e alocação de biomassa, pois a deposição de fotoassimilados é lenta e reduzida em virtude da diminuição da taxa fotossintética, tornando esses vegetais, quando desidratados, mais leves.

As doses de glyphosate aplicadas e a interação dose $\mathrm{x}$ ambiente de cultivo não influenciaram $(\mathrm{P}>0,05)$ o número de tubérculos produzidos pela tiririca. As plantas cultivadas a pleno sol foram mais eficientes na translocação e distribuição dos carboidratos para suas estruturas de reserva, quando comparadas às de sombra, aumentando a produção total de tubérculos (Tabela 3). Em média, a produção de tubérculos em plantas a pleno sol foi 16,1 e $29,5 \%$ superior à de 30 e $50 \%$ de sombra, corroborando Moosavinia \& Dore (1979), que observaram redução no número de tubérculos em plantas sombreadas, quando comparadas às de pleno sol.

A maior parte dos tubérculos produzidos foi classificada como de tamanho médio, com maior produção em plantas de tiririca mantidas a pleno sol e a 30\% de sombra (Tabela 3).

Segundo Novo et al. (2006), o tamanho dos tubérculos tem relação direta com o vigor vegetativo das plântulas recém-emergidas. A diminuição na produção de órgãos de reserva em plantas mantidas sob restrição luminosa foi observada em trabalho com taro japonês (Gondim et al., 2008). A menor produção de tubérculos de tiririca em plantas mantidas em sombreamento intensivo pode ser considerada fator relevante no manejo dessa espécie.

Houve interação significativa $(\mathrm{P} \leq 0,05)$ entre os fatores ambiente de cultivo e dose de glyphosate para o número de tubérculos germinados em leito de areia e de tubérculos inviáveis, avaliado pelo teste de tetrazólio (Tabela 4). As doses superiores a $810 \mathrm{~g} \mathrm{ha}^{-1} \mathrm{de}$ glyphosate foram responsáveis por valores acima de $93 \%$ no controle dos tubérculos de tiririca cultivados a 30 e $50 \%$ de sombra. Moosavinia \& Dore (1979) obtiveram resultados semelhantes em plantas de tiririca manejada com diferentes niveis de sombreamento e doses de glyphosate; com o aumento do estresse luminoso, ocorre diminuição significativa dos tubérculos viáveis.

Em plantas tratadas com $810 \mathrm{~g} \mathrm{ha}^{-1}$ de glyphosate e mantidas a pleno sol, a germinação dos tubérculos de tiririca foi superior à daquelas na sombra submetidas à mesma dose, que também apresentaram maior proporção de tubérculos inviáveis (Tabela 4).

Os tubérculos obtidos de plantas manejadas a $50 \%$ de sombra não germinaram e se mostraram inviáveis pelo teste de tetrazólio quando da aplicação de 1.080 e $1.350 \mathrm{~g} \mathrm{ha}^{-1}$ de glyphosate (Tabelas 4 e 5). Na literatura, vários autores relatam que, para eficiência no manejo da tiririca, há necessidade de erradicação dos tubérculos, pois estes podem permanecer por longos periodos dormentes no solo, contribuindo para a reinfestação ao longo do tempo (Miles et al., 1996; Jakelaitis et al., 2003; Silveira et al., 2010). Segundo Jakelaitis et al. (2003), os tubérculos podem sofrer dormência devido à translocação de subdoses de glyphosate, principalmente quando eles se encontram mais afastados na cadeia subterrânea.

Considerando ambos os ensaios, concluise que o aumento do sombreamento, o qual impõe adaptações a trapoeraba e a tiririca frente à superação desse estresse luminoso, torna as plantas mais suscetiveis à ação do glyphosate. O controle mais rápido e com

Tabela 3 - Produtividade de tubérculos pequeno, médio e grande provenientes de plantas submetidas a doses de glyphosate, em função do ambiente de crescimento à sombra ou a pleno sol, aos 30 DAA (dias após aplicação)

\begin{tabular}{|l|c|c|c|}
\hline \multirow{2}{*}{ Ambiente } & \multicolumn{2}{|c|}{ Número de tubérculos em função de seu tamanho } \\
\cline { 2 - 4 } & Pequenos até $0,7 \mathrm{~cm}^{\text {ns }}$ & Médios $0,7-1,4 \mathrm{~cm}$ & Grandes $1,4-2,1 \mathrm{~cm}^{\mathrm{ns}}$ \\
\hline Pleno sol & 19,90 & $52,85 \mathrm{~A}$ & 20,70 \\
\hline $30 \%$ de sombra & 13,75 & $44,75 \mathrm{AB}$ & 19,90 \\
\hline $50 \%$ de sombra & 12,10 & $34,35 \mathrm{~B}$ & 19,45 \\
\hline
\end{tabular}

Médias seguidas pelas mesmas letras na coluna não diferem entre si pelo teste de Tukey a $5 \%$ de probabilidade. ${ }^{\text {ns }}$ Não significativo a $(\mathrm{P}<0,05)$. 
Tabela 4 - Viabilidade de tubérculos provenientes de plantas submetidas a doses de glyphosate, em função do ambiente de crescimento à sombra ou a pleno sol, aos 90 DAA (dias após aplicação)

\begin{tabular}{|l|c|c|c|c|c|}
\hline \multirow{2}{*}{ Ambiente } & \multicolumn{5}{c|}{ Dose $\left(\mathrm{g} \mathrm{ha}^{-1}\right.$ de glyphosate $)$} \\
\cline { 2 - 6 } & 0 & 540 & 810 & 1.080 & 1.350 \\
\hline \multicolumn{7}{|c|}{ Tubérculos germinados } \\
\hline Pleno sol & $25,33 \mathrm{ABa}$ & $18,67 \mathrm{ABb}$ & $11,67 \mathrm{Ba}$ & $0,33 \mathrm{Ca}$ & $0,00 \mathrm{Ca}$ \\
\hline $30 \%$ de sombra & $24,67 \mathrm{Aa}$ & $26,33 \mathrm{Aa}$ & $1,00 \mathrm{Bb}$ & $0,00 \mathrm{Ba}$ & $0,33 \mathrm{Ba}$ \\
\hline $50 \%$ de sombra & $29,00 \mathrm{Aa}$ & $14,00 \mathrm{Bb}$ & $1,00 \mathrm{Cb}$ & $0,00 \mathrm{Ca}$ & $0,00 \mathrm{Ca}$ \\
\hline \multicolumn{7}{|c|}{ Tubérculos inviáveis pelo teste tetrazólio* } \\
\hline Pleno sol & $4,67 \mathrm{Ca}$ & $10,67 \mathrm{BCa}$ & $17,67 \mathrm{BCb}$ & $29,33 \mathrm{Aa}$ & $27,00 \mathrm{Aa}$ \\
\hline $30 \%$ de sombra & $4,00 \mathrm{Ba}$ & $2,67 \mathrm{Bb}$ & $28,00 \mathrm{Aa}$ & $27,67 \mathrm{Aa}$ & $25,33 \mathrm{Aa}$ \\
\hline $50 \%$ de sombra & $1,00 \mathrm{Ca}$ & $16,00 \mathrm{Ba}$ & $29,00 \mathrm{Aa}$ & $30,00 \mathrm{Aa}$ & $30,00 \mathrm{Aa}$ \\
\hline
\end{tabular}

Médias seguidas pelas mesmas letras, maiúsculas na linha e minúsculas na coluna, não diferem entre si pelo teste de Tukey a $5 \%$ de probabilidade. *Avaliação realizada nos tubérculos não germinados.

Tabela 5 - Viabilidade de tubérculos provenientes de plantas submetidas a doses de glyphosate, em função do ambiente de crescimento à sombra ou a pleno sol, aos 90 DAA (dias após aplicação)

\begin{tabular}{|l|c|}
\hline \multicolumn{1}{|c|}{ Ambiente } & $\begin{array}{c}\text { Tubérculos viáveis pelo teste } \\
\text { tetrazólio* }\end{array}$ \\
\hline Pleno sol & $0,93 \mathrm{AB}$ \\
\hline $30 \%$ de sombra & $1,99 \mathrm{~A}$ \\
\hline $50 \%$ de sombra & $0,00 \mathrm{~B}$ \\
\hline
\end{tabular}

Médias seguidas pelas mesmas letras não diferem entre si pelo teste de Tukey a $5 \%$ de probabilidade. *Avaliação realizada nos tubérculos não germinados.

menores doses de glyphosate, a redução na massa seca da parte aérea de ambas as espécies e a menor quantidade e viabilidade dos tubérculos de tiririca em ambientes com maior restrição luminosa são favoráveis ao manejo dessas importantes plantas daninhas.

\section{AGRADECIMENTOS}

À Celulose Nipo-Brasileira (CENIBRA) e À Fundação de Amparo à Pesquisa do Estado de Minas Gerais (FAPEMIG), pelo apoio financeiro na realização dos experimentos, e ao Conselho Nacional de Desenvolvimento Científico e Tecnológico (CNPq), pela bolsa concedida ao segundo autor.

\section{LITERATURA CITADA}

ASSOCIACIÓN LATINOAMERICANA DE MALEZAS ALAM. Recomendaciones sobre unificación de los sistemas de evaluación en ensayos de control de malezas. ALAM, v. 1, n. 1, p. $35-38,1974$
CLEMENTE, T. B. Efeitos da aplicação de ácido giberélico na susceptibilidade de Cyperus rotundus $\mathrm{L}$. ao glifosato. 2009. 44 f. Dissertação (Mestrado em Ciencias Biológicas - Universidade do Estado de São Paulo, Botucatu, 2009.

DURIGAN, J. C. et al. Manejo integrado da tiririca na produtividade de cana-de-açúcar. Planta Daninha, v. 24, n. 1, p. 77-81, 2006.

GOBBI, K. F. et al. Características morfológicas, estruturais e produtividade do capim-braquiária e do amendoim forrageiro submetidos ao sombreamento. R. Bras. Zootec., v. 38, n. 9, p. $1645-1654,2009$

GONDIM, A. R. O. et al. Crescimento, partição de fotoassimilados e produção de rizomas em taro cultivado sob sombreamento artificial. Hortic. Bras., v. 25, n. 3, p. 418-428, 2007.

GONDIM, A. R. O. et al. Plasticidade anatômica da folha de taro cultivado sob diferentes condições de sombreamento. Bragantia, v. 67, n. 4, p. 1037-1045, 2008.

JAKELAITIS, A. et al. Efeitos de sistemas de manejo sobre a população de tiririca. Planta Daninha, v. 21, n. 1, p. 89-95, 2003.

JEFFERIES, N.W. Herbage production on a gamble oak range in south western Colorado. J. Range Manag., v. 18, n. 2, p. 212-213, 1965.

LIMA JR., E. C. et al. Aspectos fisioanatômicos de plantas jovens de Cupania vernalis camb. submetidas a diferentes níveis de sombreamento. R. Árvore, v. 30, n. 1, p. 33-41, 2006.

MAGALHÃES, A. C. Luz no crescimento da tiririca. Bragantia, v. 26, n. 2, p. 130-141, 1967. 
MALIK, J. et al. The herbicide glyphosate. Biofactores, v. 2, p. $17-25,1989$.

MARTINS, D. et al. Controle de tiririca com sulfentrazone e diclosulam e viabilidade de tubérculos em diferentes profundidades de solo. Bragantia, v. 68, n. 2, p. 357-366, 2009.

MILES, J. E. et al. Diurnally alternating temperatures stimulates sprouting of purple nutsedge (Cyperus rotundus) tubers. Weed Sci., v. 44, p. 122-125, 1996.

MONQUERO, P. A.; CHRISTOFFOLETI, P. J. Dinâmica do banco de sementes em áreas com aplicação frequente do herbicida glyphosate. Planta Daninha, v. 21, n. 1, p. 63-69, 2003.

MONQUERO, P. A. et al. Caracterização da superfície foliar e das ceras epicuticulares em Commelina benghalensis, Ipomoea grandifolia e Amaranthus hybridus.

Planta Daninha, v. 22, n. 2, p. 203-210, 2004a

MONQUERO, P. A. et al. Absorção, translocação e metabolismo do glyphosate por plantas tolerantes e suscetíveis a este herbicida. Planta Daninha, v. 22, n. 3 p. $445-451,2004 b$.

MOOSAVINIA, H.; DORE, J. Factors affecting glyphosate activity in Imperata cylindrica (L.) Beauv. And Cyperus rotundus L. II: effect of shade. Weed Res., v. 19, n. 5, p. 321-327, 1979.

NOVO, M. C. S. S. et al. Efeito da palha de cana-de-açúcar e do tamanho do tubérculo na brotação e no desenvolvimento da parte aérea de tiririca. Bragantia, v. 65, n. 1, p. 97-107, 2006.
NOVO, M. C. S. S. et al. Interação de imazapic no sistema integrado palha de cana-de-açúcar, herbicida e vinhaça no crescimento inicial da tiririca. Planta Daninha, v. 26, n. 2 , p. 439-449, 2008.

OLIVEIRA, A. R. et al. Controle de Commelina benghalensis, C. erecta e Tripogandra diuretica na cultura do café.

Planta Daninha, v. 27, n. 4, p. 823-830, 2009.

SANTOS, I. C. et al. Eficiência de glyphosate no controle de Commelina benghalensis e Commelina diffusa. Planta Daninha, v. 19, n. 1, p. 135-143, 2001

SANTOS, I. C. et al. Caracteres anatômicos de duas espécies de trapoeraba e a eficiência do glyphosate. Planta Daninha, v. 20, n. 1, p. $1-8,2002$

SARGENT, J. A.; BLACKMAN, G. E. Studies on foliar penetration. I. Factors controlling the entry of 2,4-

dicloroacetic acid. J. Exper. Bot., v. 13, n. 3, p. 348-368, 1962.

SILVEIRA, H. R. O. et al. Alelopatia e homeopatia no manejo da tiririca (Cyperus rotundus). Planta Daninha, v. 28, n. 3, p. 499-506, 2010.

TAIZ, L.; ZEIGER, E. Fisiologia vegetal. 4.ed. Porto Alegre: Armed, 2009. 848 p.

TUFFI SANTOS, L. D. et al. Efeito do glyphosate sobre a morfoanatomia das folhas e do caule de Commelina diffusa e C. benghalensis.Planta Daninha, v. 22, n. 1, p. 101-107, 2004. 